
$\angle$ Research Square
Preprints are preliminary reports that have not undergone peer review.
They should not be considered conclusive, used to inform clinical practice, or referenced by the media as validated information.

\title{
Differences in clinical and computed tomography imaging features between two types of mixed epithelial and stromal tumor of the kidney: Suggestions for patient management
}

\author{
Juan Chen \\ Central South University \\ Hui Liu \\ Central South University \\ Meng-Si Li \\ Central South University \\ Wen-Guang Liu \\ Central South University \\ Ismail Bilal Masokano \\ Central South University

\section{Ying Peng} \\ Central South University

\section{De-Yun Feng} \\ Central South University

\section{Yi-Gang Pei} \\ Central South University
}

Wen-Zheng Li ( $\nabla$ wenzheng727@163.com)

Central South University

\section{Research Article}

Keywords: mixed epithelial and stromal tumor of the kidney, multidetector computed tomography features, clinical data, patient management, classification

Posted Date: April 2nd, 2021

DOI: https://doi.org/10.21203/rs.3.rs-350581/v1

License: (c) (i) This work is licensed under a Creative Commons Attribution 4.0 International License. Read Full License 


\section{Abstract}

Background To analyze the differences in clinical features and computed tomography characteristics in the two types of mixed epithelial and stromal tumor of the kidney (MESTK) and to establish a treatment plan for the MESTK types.

Methods 17 patients underwent multidetector computed tomography (MDCT) before surgery and had a pathological diagnosis of MESTK were enrolled. Their clinical information (R.E.N.A.L.Nephrometry Score (R.E.N.A.L.区NS), radical nephrectomy (RN), partial nephrectomy (PN), etc.) were collected. The radiological features included renal sinus fat invagination (SFI), maximal diameter (MD), capsule and septa of the tumor, etc. were also analyzed. They were divided into two types according to the $M D_{\text {solid }} / M_{\text {tumor }}$ ratio (type $A$ with $>63 \%$; type $B$ with $\leq 63 \%$ ). An independent-sample t-test and Fisher exact test were used to assess the differences between the two groups.

Results MESTKs demonstrated a variable multi-septate cystic and solid components with a delayed enhancement. There were 9 patients for type A and 8 subjects for type B. Compared with type A, the lesions in type B have larger MD

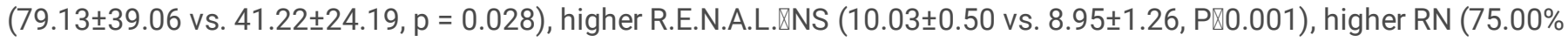
vs. $22.22 \%, p=0.015)$, larger SFI $(87.5 \%$ vs. $33.3 \%, p=0.05)$, more septa $(100 \%$ vs. $0 \%, p<0.001)$ and more capsule $(100 \%$ vs. $11.1 \%, p<0.001)$.

Conclusion Type B MESTK has more hazardous features compared with type A, suggesting that RN is more suitable for type B and PN for type A.

\section{Main Text}

Mixed epithelial and stromal tumor of the kidney (MESTK), first identified by Michal and Syrucek in 1998 (1), is a rare benign entity with a prevalence of $0.2 \%$ to $1.6 \%$ of all renal tumors $(2,3)$. Histopathologically, MESTK is composed of epithelial and stromal components (4). It appears as a cystic renal mass with varying proportions of solid components on imaging. The WHO grouped the lesion into the mixed epithelial and stromal tumor family in 2016 (5).

Surgical excision (partial nephrectomy (PN) and radical nephrectomy (RN)) is the most common treatment for patients with MESTK. PN should be recommended to preserve the nephron as much as possible in most MESTK patients because it is a benign entity. Therefore, an accurate evaluation of MESTK is vital for preoperative treatment planning. Previous studies have demonstrated the role of computed tomography (CT) and other imaging modalities including magnetic resonance imaging (MRI) and ultrasonography in evaluating the characteristics of the tumor (6-8). To the best of our knowledge, the largest radiological study on MESTK described the imaging features in eight patients (9). The classic imaging appearance of MESTK is that of a well-circumscribed, multi-septate cystic and solid mass with delayed enhancement (10-12).

In clinical work, the preoperative radiologic diagnosis of MEST is challenging and is easy to be misdiagnosed as other renal neoplasms - renal cell carcinoma (RCC) - leading to inappropriate treatment. Furthermore, it is still unclear whether the imaging features and clinical data can help make a suitable treatment plan for the patients with MESTK.

In our study, the patients with MESTK were divided into two types based on the proportion of $\mathrm{MD}_{\text {solid }} / \mathrm{MD}_{\text {tumor }}$ in the maximal slice (type A: the ratio > 63\%; type B: the percentage $\leq 63 \%$ ). Our purpose is to analyze the clinical and radiologic features of MESTK, with emphasis on evaluating the differences in clinical and computed tomography characteristics and proposing a patient management plan for the two types.

\section{Material And Methods}

\section{Patients}

Ethical approval was obtained from Institutional Review Board of the Xiangya Hospital, Central South University. This retrospective study was performed in accordance with the provisions of the Declaration of Helsinki. The requirement for informed consent was exempted by the Institutional Review Board of the Xiangya Hospital, Central South University as all data 
was analyzed anonymously (number 2018111101). From June 2011 to November 2020, 17 patients pathologically diagnosed with MESTK (13 women and 4 men囚the median age was $45.12 \pm 10.77$ years (range from 21 to $61 \mathrm{y}$ ), who underwent preoperative multidetector CT (MDCT) within 15 days before the surgical procedure were recruited. The clinical information (the follow-up time, gender, age, clinical symptoms, menstrual status, surgery methods (PN and RN), and and R.E.N.A.L. Nephrometry Score (R.E.N.A.L.खNS)) were collected ( $\mathrm{R}=$ Radius (tumor size as maximal diameter); $\mathrm{E}=$ Exophytic/endophytic properties of the tumor; $\mathrm{N}=$ Nearness of tumor deepest portion to the collecting system or sinus; $\mathrm{A}=$ Anterior (a)/posterior(p) descriptor; and $\mathrm{L}=$ Location relative to the polar line(13)). For R.E.N.A.L区NS, the range of 4 to 6,7 to 9 and 10 to 12 were deemed low, moderate and high complexity lesions, respectively. The beginning and end of the follow-up period was the time the patient had surgery and the latest MDCT or ultrasound examination in our hospital.

\section{MDCT techniques}

All patients carried out plain and contrast enhancement MDCT scan in our hospital (128 slices, Somatom Definition, Siemens Healthineers, Erlangen, Germany; 320-slice, Toshiba Aquilion ONE, Canon Medical Systems, Otawara, Tochigi, Japan). The scanning parameters were as follows: slice thickness of $1 \mathrm{~mm}$, slice gap of $0 \mathrm{~mm}$, the pitch of 1.2, 100kVp and $200 \mathrm{~mA}$ for Somatom Definition and Aquilion ONE. For enhanced MDCT, a non-ionic iodinated contrast agent (iopromide, Ultravist; Schering AG, Berlin, Germany) was used at a rate of $3.5-4 \mathrm{ml} / \mathrm{s}(1.5 \mathrm{~mL} / \mathrm{kg}, 80-100 \mathrm{ml})$. The corticomedullary phase (CMP) (30s), the nephrographic phase (NP) (70s), and the excretion phase (EP) (3- $5 \mathrm{~min}$ ) were obtained for each subject after injection of the contrast agent.

\section{Imaging analysis}

All MDCT images were transferred into the imaging workstation (Advantage

Workstation 4.4, GE Healthcare, Buc, France) and image post-processing (sagittal and coronal images) was performed. Two experienced radiologists (J.C. and G.P, reviewers 1 and 2 with 5 and 7 years of clinical experience in kidney MDCT, respectively) assessed the imaging characteristics without knowing the clinical and pathological informationखincluding the maximal diameter (MD), shape, location, calcification, septa state, mural nodule, capsule of the tumor, renal sinus fat invagination (SFI), and the enhancement degree and pattern. SFI is defined as the direct contact of the tumor with the renal sinus stroma or fat cell (14), which appears as an invasion of the fat tissue of the renal sinus on MDCT. But it is not considered invasive if the tumor impinges on (but is separated from the fat by a connective tissue layer) the perinephric or renal sinus fat (15). Enhancement patterns were evaluated and analyzed with the CT attenuation for each phase for all MESTK. A region of interest (ROI) was drawn on the solid component of the tumor (size: $40-60 \mathrm{~mm}^{2}$ ) on EP images, avoiding the cystic and calcified parts in the tumor. Then, it was copied to plain, CMP, and NP images of the same slice. For each subject, the above measurements were carried out two more times on different occasions within a week, and the average CT attenuation was calculated for each phase to obtain the enhancement pattern (wash out or delayed enhancement). Gradual enhancement pattern was considered present when the tumor attenuation in the nephrographic phase was at least $20 \mathrm{HU}$ greater than that in the corticomedullary phase (16), while gradual washout pattern was defined when the CT value of the subsequent phase was reduced to less than 20 Hounsfield units (HU) (17). The degree of enhancement was defined as the difference between the attenuation value of the unenhanced scan and the CMP. A difference higher than $50 \mathrm{HU}$ was classified as marked, between 20 and $50 \mathrm{HU}$ as moderate, and less than $20 \mathrm{HU}$ as weak enhancement (6).

A threshold value of $25 \%$ (proportion of solid components in a cyst-solid tumor) is used in the Bosniak classification (version 2019) of renal cystic masses with solid components $(18,19)$. The Bosniak classification can be used for patients with cyst-solid mass when the proportion of solid part $\leq 25 \%$. But, the Bosniak classification cannot be applied when the percentage of the solid element $>25 \%$. However, it is difficult for radiologists to estimate - qualitatively - the volume percentage of the solid part on MDCT. The volume of mass and solid components are relative to their respective diameter ( $D)\left(V=(4 / 3) \pi R^{3}\right.$ and $\left.R=D / 2\right)$, So, the maximal diameters (MD) were used to replace the corresponding volume in our study, and the equation is as follow:

Ratio $=\mathrm{MD}_{\text {solid }} / \mathrm{MD}_{\text {tumor }}$ 
where $\mathrm{MD}_{\text {tumor }}$ is the maximal diameter of tumor in the slice in which the mass has the greatest size and $M D_{\text {solid }}$ is the maximal diameter of the solid part in the same slice. When the ratio of the MD of the solid part in mass $\leq 63 \%$, it was classified into type B (can be classified with Bosniak classification), and into type A when the ratio $>63 \%$ (cannot be classified with Bosniak classification). The detailed illustration is shown in Fig.1.

For lesions classified into type B, the number of septa, septal thickness, septal enhancement, wall thickness, wall enhancement, and mural nodularity on MDCT were assessed, and Table 1 gives the reference standard during image analysis. Lesions were classified into I-IV category with Bosniak Classification(18).

\section{Statistical analysis}

An independent-sample t-test was used to assess differences in the MD, age, and R.E.N.A.L.खNS between type A and type B. The Fisher exact test was used to analyze gender, clinical symptoms, surgery methods, shape, RSI, calcification, septa, mural nodules, capsules, and enhancement patterns in the two groups. Statistical analyses were performed with SPSS 18.0 (SPSS Inc., Chicago, IL, USA). P-value $>0.05$ was considered not statistically significant

\section{Results}

\section{Clinical findings}

In the 17 patients, MESTK was detected incidentally in the majority of the patients without any symptoms $(n=10,58.82 \%)$; five patients presented with flank pain, and 2 patients presented with hematuria. MESTK occurred mainly in female $(n=13,76.5 \%)$ compared to men $(n=4,23.5 \%)$, with a predilection for perimenopausal women $(n=9,69.23 \%)$. For R.E.N.A.L.छNS, the score ranged between 7-11 with a mean score of $9.35 \pm 1.17$ (low: $n=0$; moderate: $n=7(41.18 \%)$; high: $n=10(58.82 \%)$ ) in our study. Two cases (11.76\%) showed solid components extending into the renal pelvis and ureter (Cases No. 3 and 16; Fig. 2), and both of their R.E.N.A.L.『NS were $₫ 10$. All subjects underwent surgery (PN: $n=8(47.06 \%) ; R N$ : $n=9(52.94 \%)$ ), and the longest follow-up time was 114 months. No metastasis or recurrence was found in the patients after surgery and the renal function remained normal during the follow-up period (An additional movie file shows this in more detail [see Additional file 1]). The clinical details are shown in Table 2.

\section{Imaging findings}

All MESTKs demonstrated a variable proportion of multi-septate cystic and solid components, which appeared as delayed enhancement with a well-circumscribed margin on triphasic dynamic-enhanced MDCT $(F i g ~ 3,4)$, except for two subjects that had gradual washout pattern. The CT attenuation was less than $20 \mathrm{HU}$ in the cystic part. In the 17 cases, the tumor in 14 patients (77.8\%) showed a regular shape, and 10 subjects (58.82\%) demonstrated RSI (Fig 5A). In addition, tumor capsule was present in 7 patients (41.1\%) (Fig 5B), and regular or irregular septa was present in 4 patients (22.2\%) (Fig 5C). The MDCT findings are shown in Table 3.

\section{The comparison of type A with type B}

In our study, 9 patients with MESTK were classified into type A (Fig 3) and 8 subjects into type B (Fig 4). Based on the Bosniak

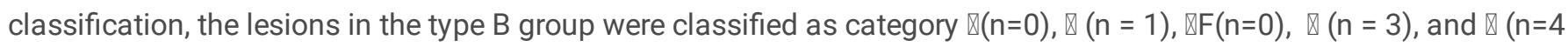

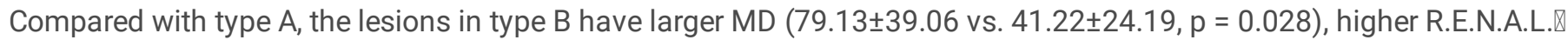
NS (10.03 \pm 0.50 vs. $8.95 \pm 1.26$, P凶0.001), higher RN (75.00\% vs.22.22\%, $p=0.015)$, greater SFI ( $87.5 \%$ vs.33.3\%, $p=0.05)$, septa $(100 \%$ vs. $0 \%, p<0.001)$ and more capsule $(100 \%$ vs. $11.1 \%, p<0.001)$. Besides, there was no significant difference between the type $A$ and $B$ groups regarding age, gender, clinical symptoms, the shape of the tumor, location of the tumor, calcification, mural nodule, and enhancement pattern (all p values $>0.05$ ) (Table 4).

\section{Discussion}


As a member of the mixed epithelial and stromal tumor family, the imaging characteristics of MESTK and its connection with patients' management remain largely unknown (5). Most of the current literature on MESTK focused on its pathologic features $(20,21)$, with only a small number of case reports and case series addressing its radiologic features $(11,22)$. In our study, 17 patients with MESTK who had an MDCT were collected-the largest imaging series to the best of our knowledgelto analyze the imaging and clinical features and with emphasis on providing a reference for patients' management based on the difference in the two types of MESTK.

The typical clinical symptomatology of MESTK includes flank pain, hematuria, or symptoms related to genitourinary infections (20). In our research, only five patients with flank pain and 2 subjects with hematuria were found in the 17 MESTK cases. However, most of them (10 patients, 58.82\%) were detected MESTK incidentally without any symptoms, which was consistent with the findings of Lane et al. (9). The possible reason may be advances in imaging modalities and the prevalence of health examinations. Also, MESTKs were found in 13 females (76.5\%): 9 of whom were perimenopausal (69.23\%). This suggests that perimenopausal females had the predominance of MESTK due to the serum estrogen level. The findings are in accordance with previous studies $(20,23,24)$.

R.E.N.A.L.-NS is a crucial scoring system for patients with renal masses, promoting a standardized communication and standardization of clinical care patterns [13]. Renal tumors with low to moderate complexity (R.E.N.A.L.INS $\leq 9$ scores) are often treated with PN, whereas RN is done for high complex lesions (R.E.N.A.L.DNS $>9$ scores) (25). In our study, the range of R.E.N.A.L. INS was 7-11 score and the mean score was $9.35 \pm 1.17$ score (low: $n=0$; moderate: $n=7$ (41.18\%); high: $n=10$ (58.82\%)). 7 patients (R.E.N.A.L. $\mathrm{NSS} \leq 9$ score) underwent PN and 9 patients (R.E.N.A.L. $\square$ NS $\otimes 9$ score) had RN. Only one patient ( case 16, R.E.N.A.L. $\square$ NS $=10$ score) chose PN due to the patient's strong desire to preserve the kidney and because the tumor was located mainly in the pelvis and ureter. Also, there were no signs of recurrence or metastasis for all patients during the follow-up time, although the metastasis of MESTK has been reported (26). It indicated that the choice of treatment is successful for all persons.

MESTKs are unilateral and single lesions with different proportions of solid components $(8,11,12,16)$. Our cases demonstrated well-circumscribed expansile lesions with a variable proportion of multi-septate cystic and solid components, having delayed enhancement on triphasic dynamic-enhanced MDCT. The delayed enhancement may be related to the abundance of collagen fibers, which restrict the diffusion of contrast agent within the tumor $(4,17)$. Lane et al. found that MESTK commonly tends to extend into the renal sinus (9). In our study, 10 subjects (55.5\%) have demonstrated SFI, indicating that nephron-sparing surgery is not the best management plan for such tumors compared to those without the SFI.

In our study, Type A in MESTK is composed mainly of solid elements ( $>63 \%$ for the ratio of the solid components' MD in the mass), while Type B consists principally of the cystic part ( $\leq 63 \%$ for the percentage of the solid element' MD in the tumor). Interestingly, the MD of tumor in type B was greater than Type A. The reason may be that epithelial elements existed more in type $B$ than type A. These epithelia then secret fluid that accumulates in many various cysts due to the epithelial cells containing much spatulate papillary architectures and tiny crowded glands(4). In addition, our findings showed that R.E.N.A.L-NS in type B was higher than type $A(10.03 \pm 0.50$ vs. $8.95 \pm 1.26, P \otimes 0.001)$, which implies that patients in type $B$ had a higher risk for urine leakage when $\mathrm{PN}$ is performed (27). Fortunately, the patients with type $\mathrm{B}$ underwent RN and therefore had no urine leakage.

SFI is not currently used in either the Robson or TNM staging systems. However, it is an important prognostic finding and staging parameter (14). Roberto et al. deemed that SFI significantly influenced disease-free survival and cancer-specific survival in patients without nodal or distant metastases (15). Stephen et al. suggested that RN should be recommended for those patients with renal sinus invasion (14). It is in line with our findings that 7 out of 8 patients (type B) with SFI had RN. Furthermore, type B had more septa than type $A$ and met the Bosniak classification requirement, but type $A$ did not satisfy it. Thus, MESTK Type B in our study presents as a multiloculated lesion with regular or irregular septa, which is different from type A (28). In addition, type $B$ lesions have more capsules, caused by compression of adjacent renal tissue by the tumors correlating with the larger size of these tumors $(29,30)$.

Limitations of this study are the small number of MESTK cases, retrospective design, and single-center study. With advances in imaging modalities and the rising popularity of health examination, diagnosis of asymptomatic and small MESTK will increase

Page 5/16 
and promote a better treatment plan for patients' management.

\section{Conclusion}

In general, MESTK presents as a well-circumscribed lesion with a variable proportion of multi-septate cystic and solid components, showing a delayed enhancement on triphasic dynamic-enhanced MDCT. With a comparison of type A, type $B$ MESTK has more hazardous features, such as larger MD, higher R.E.N.A.L.-NS, more RN, greater SFI, multiple septa, which suggests that RN is more suitable for type B lesions. Nephron-sparing surgery should be considered for type A cases.

\section{Declarations}

\section{Ethics approval and consent to participate}

Ethical approval was obtained from Institutional Review Board of the Xiangya Hospital, Central South University. This retrospective study was performed in accordance with the provisions of the Declaration of Helsinki. The requirement for informed consent was exempted by the Institutional Review Board of the Xiangya Hospital, Central South University as all data was analyzed anonymously (number 2018111101).

\section{Consent for publication}

Not applicable.

\section{Availability of data and materials}

The datasets used and/or analysed during the current study available from the corresponding author on reasonable request.

\section{Competing interests}

The authors declare that they have no competing interests.

\section{Funding}

This study has received funding by the Hunan Science and Technology Department Plan Project (grant number 2018XK2304); the National Natural Science Foundation of China (grant number 82071895); and China Postdoctoral Science Foundation (grant number: 2019M652807, Beijing, China).

\section{Authors' contributions}

JC, HL, YGP and WZL conceived and designed the study. JC, MSL and HL collected and analyzed the data. WGL and IBM contributed analysis tools. YP and DYF performed the histological examination of the cancer. JC, HL, YGP and WZL provided critical inputs on design, analysis, and interpretation of the study. All the authors had access to the data. All authors read and approved the final manuscript as submitted.

\section{Acknowledgements}

Not applicable.

\section{Authors' information}

${ }^{1}$ Department of Radiology, Xiangya Hospital, Central South University, Changsha, 410008, China.

2 Department of Pathology, Xiangya Hospital, Central South University, Changsha, 410008, China.

${ }^{3}$ Postdoctoral Fellow, Xiangya Hospital, Central South University, Changsha, Hunan, 410008, P.R. China. 


\section{Abbreviations}

\section{MESTK}

mixed epithelial and stromal tumor of the kidney

\section{R.E.N.A.L.-NS}

R.E.N.A.L.Nephrometry Score

\section{PN}

partial nephrectomy

RN

radical nephrectomy

\section{SFI}

sinus fat invagination

\section{MD}

maximal diameter

MDCT

multidetector computed tomography

CMP

corticomedullary phase

NP

nephrographic phase

EEP

excretory phase

\section{References}

1. Michal M, Syrucek M. Benign mixed epithelial and stromal tumor of the kidney. Pathol Res Pract. 1998;194(6):445-8.

2. Eric Simpson, Shalini Koppisetty, Ricardo C Alessio, Kumar A. Mixed epithelial and stromal tumour of the kidney. BMJ Case Rep. 2015;2015.

3. Terao H, Makiyama K, Yanagisawa. M. Mixed epithelial and stromal tumor of kidney: a case report. Hinyokika Kiyo. 2009;55(8):495-8.

4. Caliò A, Eble JN, Grignon DJ, B. D. Mixed Epithelial and Stromal Tumor of the Kidney: A Clinicopathologic Study of 53 Cases. Am J Surg Pathol. 2016;40(11):1538-49.

5. Moch H, Cubilla AL, Humphrey PA, Reuter VE, Ulbright TM. The 2016 WHO Classification of Tumours of the Urinary System and Male Genital Organs-Part A: Renal, Penile, and Testicular Tumours. Eur Urol. 2016;70(1):93-105.

6. Ning Lang, Jie Li, Jian-Yu Liu, Xiang-Zhu Zeng, Yang Y. Mixed Epithelial and Stromal Tumor of the Kidney: An Analysis of Multidetector Computed Tomography Manifestations and Clinicopathologic Findings. J Comput Assist Tomogr. 2010;34(2):177-81.

7. Colombo P, Naspro R, Vallieri L, Vavassori I, Valenti S, Galli C, et al. Non-hormone-induced mixed epithelial and stromal tumor of kidney in a man: description of a rare case. Urology. 2008;71(1):168 e7-9.

8. Park HS, Kim SH, Kim SH, Paik JH, Hwang SI, Jung SI, et al. Benign mixed epithelial and stromal tumor of the kidney: imaging findings. J Comput Assist Tomogr. 2005;29(6):786-9.

9. Lane BR, Campbell SC, Remer EM, Fergany AF, Williams SB, Novick AC, et al. Adult cystic nephroma and mixed epithelial and stromal tumor of the kidney: clinical, radiographic, and pathologic characteristics. Urology. 2008;71(6):1142-8.

10. Wood CG, 3rd, Casalino DD. Mixed epithelial and stromal tumor of the kidney. J Urol. 2011;186(2):677-8.

11. Sahni VA, Mortele KJ, Glickman J, Silverman SG. Mixed epithelial and stromal tumour of the kidney: imaging features. BJU Int. 2010;105(7):932-9. 
12. Chu LC, Hruban RH, Horton KM, EK. F. Mixed epithelial and stromal tumor of the kidney: radiologic-pathologic correlation. Radiographics. 2010;30(6):1541-51.

13. Kutikov A, Uzzo RG. The R.E.N.A.L. nephrometry score: a comprehensive standardized system for quantitating renal tumor size, location and depth. J Urol. 2009;182(3):844-53.

14. Bonsib SM, Gibson D, Mhoon M, Greene GF. Renal sinus involvement in renal cell carcinomas. Am J Surg Pathol. 2000;24(3).

15. Bertini R, Roscigno M, Freschi M, Strada E, Petralia G, Pasta A, et al. Renal sinus fat invasion in pT3a clear cell renal cell carcinoma affects outcomes of patients without nodal involvement or distant metastases. J Urol. 2009;181(5):2027-32.

16. Millet I, Doyon FC, Hoa D, Thuret R, Merigeaud S, Serre I, et al. Characterization of small solid renal lesions: can benign and malignant tumors be differentiated with CT? AJR Am J Roentgenol. 2011;197(4):887-96.

17. Yi X, Wang J, Zhang Y, Wang Z, Zhang Z, Gong G, et al. Renal solitary fibrous tumor/hemangiopericytoma: computed tomography findings and clinicopathologic features. Abdom Radiol (NY). 2019;44(2):642-51.

18. Silverman SG, Pedrosa I, Ellis JH, Hindman NM, Schieda N, Smith AD, et al. Bosniak Classification of Cystic Renal Masses, Version 2019: An Update Proposal and Needs Assessment. Radiology. 2019;292(2):475-88.

19. Smith AD, Abou Elkassem A. Approach to Renal Cystic Masses and the Role of Radiology. Radiol Clin North Am. 2020;58(5):897-907.

20. Adsay NV, Eble JN, Srigley JR, Jones EC, DJ. G. Mixed epithelial and stromal tumor of the kidney. Am J Surg Pathol. 2000;24(7):958-70.

21. Michal M, Hes O, Bisceglia M, Simpson RH, Spagnolo DV, Parma A, et al. Mixed epithelial and stromal tumors of the kidney. A report of 22 cases. Virchows Arch. 2004;445(4):359-67.

22. Prasad SR, Surabhi VR, Menias CO, Raut AA, Chintapalli KN. Benign renal neoplasms in adults: cross-sectional imaging findings. AJR Am J Roentgenol. 2008;190(1):158-64.

23. Liu C-H, Yu C-C, Chang C-R, Wu TT, Huang J-K. Mixed Epithelial and Stromal Tumor of the Kidney With Elevated Serum Level of Cancer Antigen 125. Journal of the Formosan Medical Association. 2011;110(2):125-8.

24. Mohanty SK, AV. P. Mixed epithelial and stromal tumors of the kidney: an overview. Arch Pathol Lab Med. 2009;133(9):1483-6.

25. Naya Y, Kawauchi A, Oishi M, Ueda T, Fujihara A, Naito Y, et al. Comparison of diameter-axial-polar nephrometry and RENAL nephrometry score for treatment decision-making in patients with small renal mass. Int J Clin Oncol. 2015;20(2):358-61.

26. Bakavičius A, Barisienè M, Snicorius M, Valančienè D, Dasevičius D, Žalimas A, et al. Malignant mixed epithelial and stromal tumour of the kidney: a case report and a literature review. Acta Med Litu. 2018;25(1):31-7.

27. Bruner B, Breau RH, Lohse CM, Leibovich BC, Blute ML. Renal nephrometry score is associated with urine leak after partial nephrectomy. BJU Int. 2011;108(1).

28. Wang C-j, Lin Y-w, Xiang H, Fang D-b, Jiang P, Shen B-h. Mixed epithelial and stromal tumor of the kidney:report of eight cases and literature review. World J Surg Oncol. 2013;11(1):207.

29. Minervini A, di Cristofano C, Lapini A, Marchi M, Lanzi F, Giubilei G, et al. Histopathologic Analysis of Peritumoral Pseudocapsule and Surgical Margin Status after Tumor Enucleation for Renal Cell Carcinoma. European Urology. 2009;55(6):1410-8.

30. Takagi T, Yoshida K, Kondo T, Kobayashi H, lizuka J, Okumi M, et al. Peritumoral pseudocapsule status according to pathological characteristics from robot-assisted laparoscopic partial nephrectomy for localized renal cell carcinoma. Int J Urol. 2019;26(4):446-50.

\section{Tables}


Table 1. The standard classification of MESTK lesions with MDCT

Type A: unsuitable for the application of Bosniak Classification (version 2019)

Type B: can be classified with Bosniak Classification (version 2019)

[ Well-defined cystic mass with thin ( $\leq 2 \mathrm{~mm}$ ) smooth wall; homogeneous fluid (-9 to $20 \mathrm{HU}$ ); no septa or calcifications; wall may enhance

․ Six types, all well-defined with thin $(\leq 2 \mathrm{~mm})$ smooth walls:

1. Cystic masses with thin ( $\leq 2 \mathrm{~mm})$ and few (1-3) septa; septa and wall may enhance; may have calcification of any type*

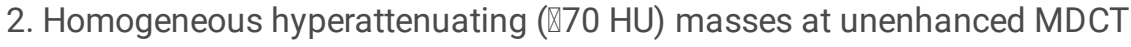

3. Homogeneous non-enhancing masses $₫ 20 \mathrm{HU}$ at renal mass protocol MDCT, may have calcification of any type

4. Homogeneous masses -9 to $20 \mathrm{HU}$ at unenhanced MDCT

5. Homogeneous masses 21 to $30 \mathrm{HU}$ at portal venous phase MDCT

6. Homogeneous low-attenuation masses that are too small to characterize

QF Three types, cystic masses with enhancing wall or enhancing septa:

1. Cystic masses with a smooth minimally thickened $(3 \mathrm{~mm})$ enhancing wall

2. Cystic masses smooth minimal thickening $(3 \mathrm{~mm})$ of one or more enhancing septa

3. Cystic masses with many $(\geq 4)$ smooth thin $(\leq 2 \mathrm{~mm})$ enhancing septa

[ One or more enhancing thick ( $\geq 4 \mathrm{~mm}$ width) or enhancing irregular (displaying $\leq 3-\mathrm{mm}$ obtusely margined convex protrusion[s]) walls or septa

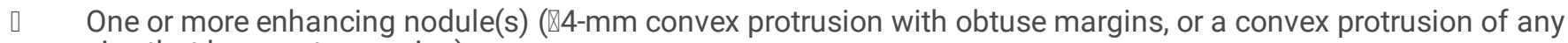
size that has acute margins)

*Renal masses have abundant thick or nodular calcifications on MDCT; \#Renal tumors are hyperattenuating, homogeneous, nonenhancing, and larger than $3 \mathrm{~cm}$ on MDCT. 
Table 2. Clinical features of the 17 patients with MESTK

\begin{tabular}{|c|c|c|c|c|c|c|c|c|c|c|c|}
\hline \multirow{2}{*}{$\begin{array}{l}\text { Case } \\
\text { No. }\end{array}$} & \multirow{2}{*}{$\begin{array}{l}\text { Follow-up } \\
\text { (months) } \\
\text { Begin and end } \\
\text { time }\end{array}$} & \multirow{2}{*}{$\begin{array}{l}\text { Gender/ } \\
\text { Age } \\
\text { (years) }\end{array}$} & \multirow[t]{2}{*}{ Symptoms } & \multirow{2}{*}{$\begin{array}{l}\text { Menstrual } \\
\text { Status }\end{array}$} & \multirow[t]{2}{*}{ Surgery } & \multirow{2}{*}{$\begin{array}{l}\text { Creatinine level } \\
\text { Before/ after } \\
\text { surgery } \\
\text { (umol/l) }\end{array}$} & \multicolumn{5}{|c|}{ R.E.N.A.L. $\mathbb{N N S}$} \\
\hline & & & & & & & $\mathrm{R}$ & E & $\mathrm{N}$ & L & $\begin{array}{l}\text { Total } \\
\text { score }\end{array}$ \\
\hline 1 & $\begin{array}{l}2 \text { (Jul,2020- } \\
\text { Sep,2020) }\end{array}$ & $M / 26$ & Incidental & $\mathrm{N}$ & PN & $85.7 / 107.0$ & 3 & 2 & 3 & 1 & 9 \\
\hline 2 & $\begin{array}{l}6 \text { (Mar,2019- } \\
\text { Sep,2019) }\end{array}$ & $M / 52$ & Incidental & $\mathrm{N}$ & PN & $96.0 / 118.0$ & 3 & 3 & 1 & 1 & 8 \\
\hline 3 & $\begin{array}{l}9 \text { (Feb,2019- } \\
\text { Jun,2020) }\end{array}$ & $F / 56$ & Flank pain & Post- & RN & $59.0 / 53.0$ & 2 & 3 & 3 & 3 & 11 \\
\hline 4 & $\begin{array}{l}16 \text { (Jul, } 2018 \text { - } \\
\text { Dec,2019) }\end{array}$ & $F / 45$ & Incidental & Peri- & $\mathrm{RN}$ & $88.7 / 98.3$ & 3 & 2 & 3 & 2 & 10 \\
\hline 5 & $\begin{array}{l}24 \text { (Feb,2018- } \\
\text { Feb,2020) }\end{array}$ & $F / 53$ & Incidental & Post- & RN & 72.2/102.0 & 3 & 2 & 3 & 2 & 10 \\
\hline 6 & $\begin{array}{l}29 \text { (Jun,2017- } \\
\text { Nov,2019) }\end{array}$ & $F / 53$ & Incidental & Post- & PN & $82.0 / 69.0$ & 1 & 3 & 1 & 2 & 7 \\
\hline 7 & $\begin{array}{l}30 \text { (Jun,2017- } \\
\text { Dec,2019) }\end{array}$ & $F / 49$ & Incidental & Peri- & $\mathrm{RN}$ & $64.2 / 106.2$ & 3 & 2 & 3 & 3 & 11 \\
\hline 8 & $\begin{array}{l}30 \text { (Jun,2017- } \\
\text { Dec,2019) }\end{array}$ & $F / 34$ & Haematuria & Pre- & $\mathrm{RN}$ & 61.5/73.2 & 1 & 3 & 3 & 3 & 10 \\
\hline 9 & $\begin{array}{l}31 \text { (Aug,2017 - } \\
\text { Mar,2020) }\end{array}$ & M/35 & Incidental & $\mathrm{N}$ & PN & $58.0 / 74.3$ & 1 & 3 & 1 & 3 & 8 \\
\hline 10 & $\begin{array}{l}35 \text { (Nov,2016- } \\
\text { Oct,2019) }\end{array}$ & $F / 42$ & Incidental & Peri- & PN & $67.0 / 90.0$ & 1 & 3 & 1 & 3 & 8 \\
\hline 11 & $\begin{array}{l}39(\text { Sep,2016- } \\
\text { Nov,2019) }\end{array}$ & $\mathrm{F} / 44$ & Haematuria & Peri & $\mathrm{RN}$ & $99.0 / 131.0$ & 2 & 2 & 3 & 3 & 10 \\
\hline 12 & $\begin{array}{l}43 \text { (Sep,2016 } \\
-2020.03)\end{array}$ & $M / 61$ & Flank pain & $\mathrm{N}$ & $\mathrm{RN}$ & 109.7/130.0 & 2 & 2 & 3 & 3 & 10 \\
\hline 13 & $\begin{array}{l}45 \text { (Feb,2015 - } \\
\text { Nov,2018) }\end{array}$ & $\mathrm{F} / 52$ & Incidental & Peri & PN & $54.0 / 88.3$ & 1 & 3 & 1 & 3 & 8 \\
\hline 14 & $\begin{array}{l}50 \text { (Jul,2014 - } \\
\text { Sep,2018) }\end{array}$ & $F / 43$ & Incidental & Peri- & $\mathrm{RN}$ & 73.0/108.0 & 2 & 2 & 3 & 3 & 10 \\
\hline 15 & $\begin{array}{l}59 \text { (Jun,2014- } \\
2019.05)\end{array}$ & $\mathrm{F} / 49$ & Flank pain & Peri- & $\mathrm{RN}$ & $78.4 / 96.3$ & 1 & 3 & 3 & 3 & 10 \\
\hline 16 & $\begin{array}{l}60 \text { (May,2013- } \\
\text { May,2018) }\end{array}$ & $\mathrm{F} / 52$ & Flank pain & Peri- & PN & 77.0/90.3 & 1 & 3 & 3 & 3 & 10 \\
\hline 17 & $\begin{array}{l}\text { 114(May,2011- } \\
\text { Nov,2020) }\end{array}$ & $F / 21$ & Flank pain & Pre- & PN & $59.6 / 68.5$ & 3 & 1 & 2 & 3 & 9 \\
\hline
\end{tabular}

Note: pre- = premenopausal; peri- = perimenopausal; post-=postmenopausal; $P N=$ partial nephrectomy; RN=radical nephrectomy; The number in the parentheses was the beginning and endpoint of follow-up time; The creatinine level was normal from 53 to $132.6 \mathrm{umol} /$; ; The score standard for the evaluation of R.E.N.A.L. $\mathbb{W N S}$ as follow: 1 point ( $R \leq 40 \mathrm{~mm} ; E \geq$ $50 \%$; $>7 \mathrm{~mm}$; or L: entirely above the upper or below the lower polar line); 2 points $(40<\mathrm{R}<70 \mathrm{~mm} ; \mathrm{E}<50 \% ; 4 \mathrm{~mm}<\mathrm{N}<7 \mathrm{~mm}$; or $\mathrm{L}$ : lesion crosses polar line); 3points $(\mathrm{R} \geq 70 \mathrm{~mm}$; $\mathrm{E}=$ Entirely endophytic; $\mathrm{N} \leq 4 \mathrm{~mm}$; $\mathrm{L}:>50 \%$ of mass is across polar line or mass crosses the axial renal midline or mass is entirely between the polar lines) [13]. 


\begin{tabular}{|c|c|c|c|c|c|c|c|c|c|c|c|}
\hline $\begin{array}{l}\text { Case } \\
\text { No. }\end{array}$ & Type & $\mathrm{BC}$ & $\mathrm{MD}(\mathrm{mm})$ & Shape & Location & SFI & Calcification & Septa & $\begin{array}{l}\text { Mural } \\
\text { nodule }\end{array}$ & Capsule & $\begin{array}{l}\text { Enhancement } \\
\text { pattern }\end{array}$ \\
\hline 1 & $A$ & NA & 75 & Re- & $\mathrm{R}-1$ & $\mathrm{~N}$ & $\mathrm{~N}$ & $\mathrm{~N}$ & $\mathrm{~N}$ & $\mathrm{~N}$ & GE \\
\hline 2 & $A$ & NA & 70 & Re- & $\mathrm{L}-1$ & $\mathrm{~N}$ & $\mathrm{Y}$ & $\mathrm{N}$ & $\mathrm{N}$ & $\mathrm{N}$ & GE \\
\hline 3 & $A$ & NA & 43 & Re- & $\mathrm{R}-3$ & $\mathrm{Y}$ & $\mathrm{N}$ & $\mathrm{N}$ & $\mathrm{N}$ & $\mathrm{N}$ & GE \\
\hline 4 & B & III & 112 & Irre- & $\mathrm{R}-2$ & $\mathrm{Y}$ & $\mathrm{N}$ & Re- & $\mathrm{N}$ & $\mathrm{Y}$ & GE \\
\hline 5 & B & III & 75 & Re- & $\mathrm{L}-2$ & $Y$ & $\mathrm{Y}$ & Re- & $\mathrm{N}$ & $Y$ & GE \\
\hline 6 & $A$ & NA & 21 & Re- & $\mathrm{R}-2$ & $\mathrm{~N}$ & $\mathrm{~N}$ & $\mathrm{~N}$ & $\mathrm{~N}$ & $\mathrm{~N}$ & GW \\
\hline 7 & $\mathrm{~B}$ & IV & 109 & Irre- & L-3 & $Y$ & $\mathrm{~N}$ & Irre- & Y & $Y$ & GW \\
\hline 8 & B & IV & 39 & Re- & L-3 & $\mathrm{Y}$ & $\mathrm{N}$ & Irre- & $\mathrm{N}$ & $\mathrm{N}$ & GE \\
\hline 9 & $A$ & NA & 8 & $\mathrm{Re}-$ & $\mathrm{L}-3$ & $\mathrm{~N}$ & $\mathrm{~N}$ & $\mathrm{~N}$ & $\mathrm{~N}$ & $\mathrm{~N}$ & GE \\
\hline 10 & $A$ & NA & 27 & $\mathrm{Re}-$ & L-3 & $\mathrm{N}$ & $\mathrm{N}$ & $\mathrm{N}$ & $\mathrm{N}$ & $\mathrm{N}$ & GE \\
\hline 11 & B & III & 64 & $\mathrm{Re}^{-}$ & $\mathrm{R}-3$ & $Y$ & $\mathrm{~N}$ & $\mathrm{Re}-$ & $\mathrm{N}$ & $Y$ & GE \\
\hline 12 & $B$ & IV & 52 & Irre- & $\mathrm{R}-3$ & $Y$ & $Y$ & Irre- & $Y$ & $Y$ & GE \\
\hline 13 & $A$ & NA & 29 & $\mathrm{Re}-$ & L-3 & $\mathrm{N}$ & $\mathrm{N}$ & $\mathrm{N}$ & $\mathrm{N}$ & $\mathrm{N}$ & $\mathrm{GE}$ \\
\hline 14 & $A$ & NA & 68 & $\mathrm{Re}-$ & $\mathrm{R}-3$ & $Y$ & $\mathrm{~N}$ & $\mathrm{~N}$ & $\mathrm{~N}$ & $\mathrm{~N}$ & GE \\
\hline 15 & B & IV & 37 & Re- & L-3 & $Y$ & $\mathrm{~N}$ & Irre- & $\mathrm{N}$ & $Y$ & GE \\
\hline 16 & $A$ & NA & 30 & $\mathrm{Re}-$ & $\mathrm{R}-3$ & $Y$ & $\mathrm{Y}$ & $\mathrm{N}$ & $\mathrm{N}$ & $\mathrm{N}$ & GE \\
\hline 17 & B & II & 145 & $\mathrm{Re}-$ & L-3 & $\mathrm{N}$ & $\mathrm{N}$ & $\mathrm{Re}-$ & $\mathrm{N}$ & $Y$ & GE \\
\hline \multicolumn{12}{|c|}{ 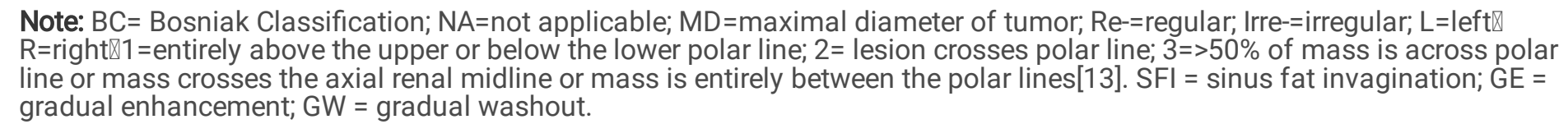 } \\
\hline
\end{tabular}

Table 4. The comparison between two types of MESTK 


\begin{tabular}{|c|c|c|c|}
\hline & Type A(n=9) & Type B $(n=8)$ & P-value \\
\hline \multicolumn{4}{|c|}{ Clinical features } \\
\hline Age(y) & $45.67 \pm 10.01$ & $44.50 \pm 12.24$ & 0.834 \\
\hline $\mathrm{MD}(\mathrm{mm})$ & $41.22 \pm 24.19$ & $79.13 \pm 39.06$ & $0.028^{*}$ \\
\hline R.E.N.A.L.-NS & $8.95 \pm 1.26$ & $10.03 \pm 0.50$ & $<0.001^{*}$ \\
\hline Gender & & & 0.576 \\
\hline $\mathrm{F}$ & $6 \otimes 66.67 \% \rrbracket$ & $7 \rrbracket 87.50 \% \rrbracket$ & \\
\hline M & $3 \llbracket 33.33 \% \rrbracket$ & $1 \otimes 12.50 \% \bigotimes$ & \\
\hline \multicolumn{3}{|c|}{ Clinical symptoms } & 0.347 \\
\hline $\mathrm{Y}$ & $3 \varangle 33.33 \% \rrbracket$ & $5 \rrbracket 62.50 \% \rrbracket$ & \\
\hline $\mathrm{N}$ & $6 \rrbracket 66.67 \% \rrbracket$ & $3 \rrbracket 37.50 \% \rrbracket$ & \\
\hline \multicolumn{3}{|c|}{ Surgery methods } & $0.015^{*}$ \\
\hline PN & $7 \otimes 77.78 \% \bigotimes$ & $1 \rrbracket 25.00 \% \rrbracket$ & \\
\hline $\mathrm{RN}$ & $2 \rrbracket 22.22 \% \rrbracket$ & $7 \rrbracket 75.00 \% \rrbracket$ & \\
\hline \multicolumn{4}{|l|}{ MDCT features } \\
\hline Shape & & & 0.082 \\
\hline Re- & $9 \otimes 100.00 \% \rrbracket$ & $5 \rrbracket 62.50 \% \rrbracket$ & \\
\hline Irre- & $0(0.00 \%)$ & $3 \rrbracket 37.50 \% \rrbracket$ & \\
\hline Location & & & 0.637 \\
\hline$L$ & $4 \llbracket 44.44 \% \rrbracket$ & $5 \llbracket 62.50 \% \rrbracket$ & \\
\hline $\mathrm{R}$ & $5 \bigotimes 55.56 \% \rrbracket$ & $3 \rrbracket 37.50 \% \rrbracket$ & \\
\hline SFI & & & $0.050^{*}$ \\
\hline $\mathrm{Y}$ & $3 \llbracket 33.33 \% \rrbracket$ & $7 \llbracket 87.50 \% \rrbracket$ & \\
\hline $\mathrm{N}$ & $6 \bigotimes 66.67 \% \rrbracket$ & $1 \otimes 12.50 \% \bigotimes$ & \\
\hline Calcification & & & 1.000 \\
\hline Y & $2 \varangle 22.22 \% \rrbracket$ & $2 \varangle 25.00 \% \rrbracket$ & \\
\hline $\mathrm{N}$ & $7 \nabla 77.78 \% \rrbracket$ & $6 \otimes 75.00 \% \bigotimes$ & \\
\hline Septa & & & $<0.001^{*}$ \\
\hline Y & $0(0.00 \%)$ & $8 \otimes 100.00 \% \rrbracket$ & \\
\hline $\mathrm{N}$ & $9 \rrbracket 100.00 \% \rrbracket$ & $0(0.00 \%)$ & \\
\hline Mural nodule & & & 0.206 \\
\hline Y & $0(0.00 \%)$ & $2 \varangle 25.00 \% \rrbracket$ & \\
\hline $\mathrm{N}$ & $9 \rrbracket 100.00 \% \rrbracket$ & $6 \bigotimes 75.00 \% \rrbracket$ & \\
\hline Capsule & & & $<0.001^{*}$ \\
\hline $\mathrm{Y}$ & $0(0.00 \%)$ & $7 \rrbracket 87.50 \% \rrbracket$ & \\
\hline
\end{tabular}

Page 12/16 


\begin{tabular}{|c|c|c|c|}
\hline $\mathrm{N}$ & $9 \rrbracket 100.00 \% \bigotimes$ & $1 \rrbracket 12.50 \% \bigotimes$ & \\
\hline \multicolumn{3}{|c|}{ Enhancement pattern } & 0.131 \\
\hline Het- & $8 \llbracket 89.89 \% \rrbracket$ & $4 \llbracket 50.00 \% \rrbracket$ & \\
\hline Hom- & 1ब11.11\%区 & $4 \llbracket 50.00 \% \rrbracket$ & \\
\hline
\end{tabular}

Note: * ${ }^{*}$ P value beyond 0.050खMD=maximal diameter of tumor; SFI=sinus fat invaginationखR.E.N.A.L.-NS = R.E.N.A.L.-System score; Re-=regular; Irre-=irregular; Het-=heterogeneous; Hom-=homogeneous; $Y=y e s \llbracket N=$ no.

\section{Figures}
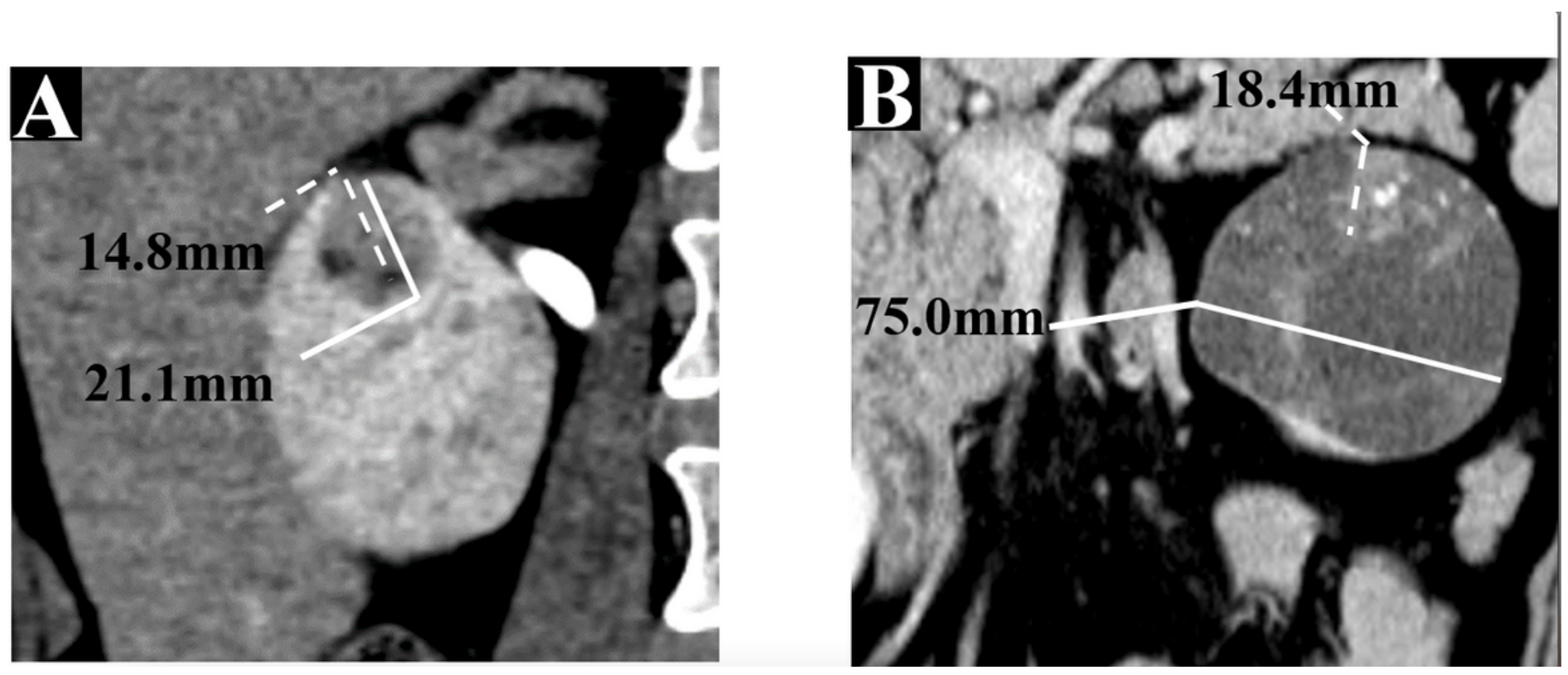

Figure 1

An example of lesion classification into type A and type B based on the proportion of solid components. In the Fig.1A (case 6), the maximum diameter of the mass (solid line) is $21.1 \mathrm{~mm}$, and the longest diameter of the solid component (dotted line) is $14.8 \mathrm{~mm}$ in the same slice. Thus, the ratio is $70.1 \% \bigotimes 14.8 / 21.1$ \according to the equation (Ratio = MDsolid / MDtumor), which is more than $63 \%$ and classified into Type A. In Fig.1B (case 5), the maximum diameter of the mass (solid line) is $75 \mathrm{~mm}$, and the longest diameter of the solid part (dotted line) is $18.4 \mathrm{~mm}$. Thus, the ratio is $24.5 \%(18.4 / 75)$ and classified into Type $B$ (the ratio $<50 \%$ ) on the basis of the equation (Ratio = MDsolid / MDtumor). 


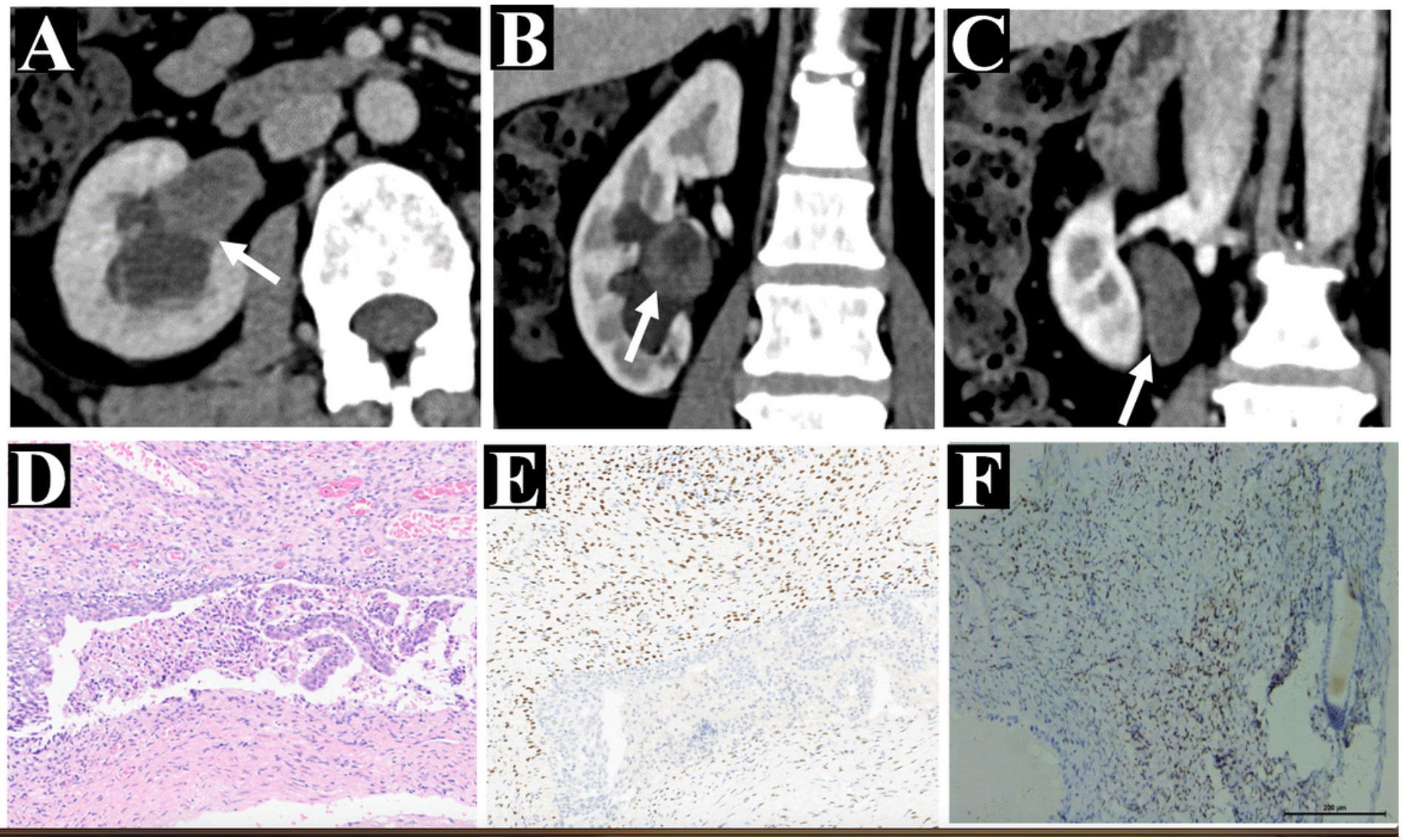

Figure 2

A 56-year-old woman with confirmed MESTK by pathological examination of surgical specimen (Case 3). Axial (Fig 2A) and coronal (Fig 2B, 2C) MDCT images in the excretory phase. The images show the solid-predominant mass extending into the pelvis and ureter (white arrow), which was confirmed histologically, Fig 2D (histopathological staining: consisted of the epithelium and stroma in the microscopy), Fig 2E (Immunohistochemical staining: positive for Estrogen receptors, represents the stromal element) and Fig 2F (Immunohistochemical staining: progesterone receptor-positive, illustrates the stromal cells).
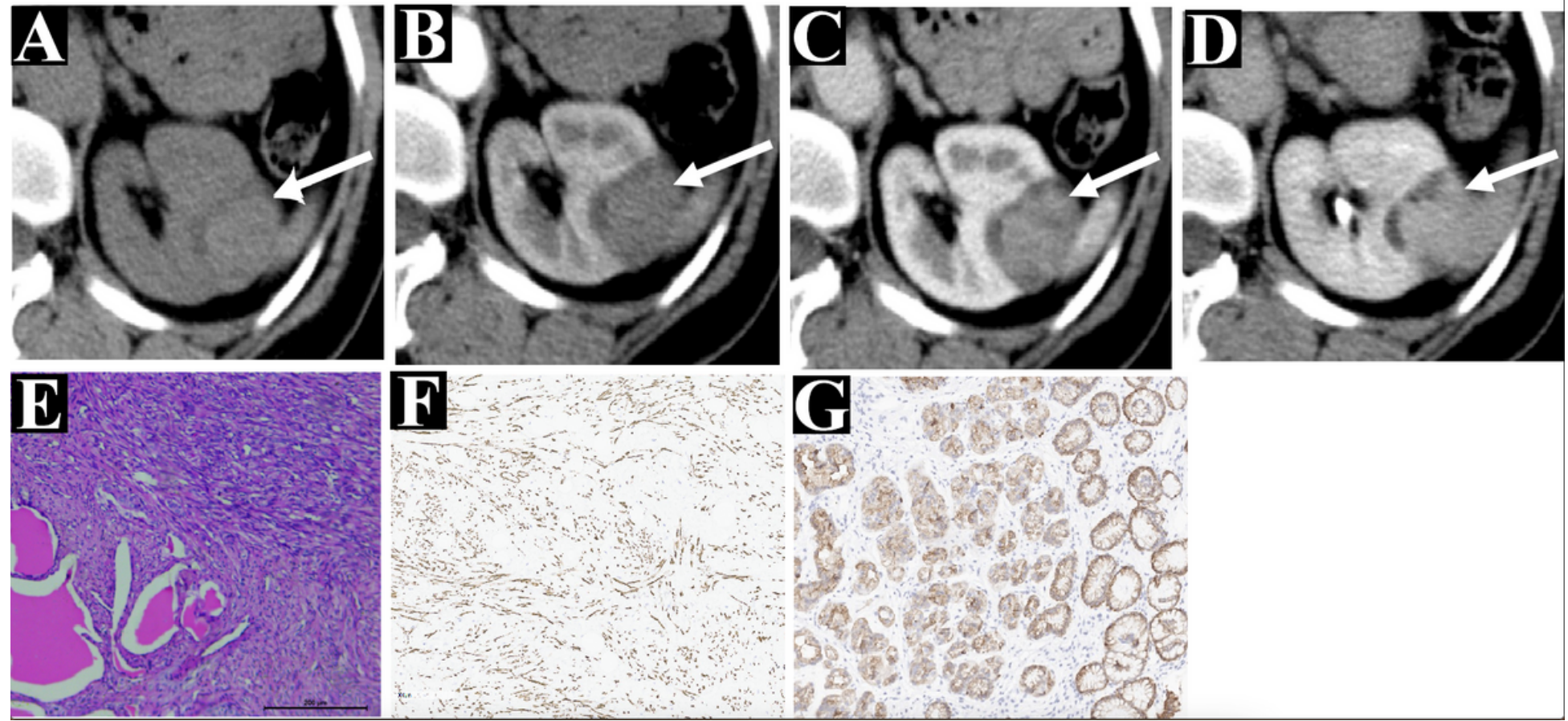
Figure 3

A 52-year-old woman with flank pain (Case 13). A slightly hyperdense solid mass in the left kidney was found on the axial unenhanced MDCT (Fig 3A), which shows no enhancement on the corticomedullary phase (Fig 3B), slight enhancement on the nephrographic phase (Fig 3C), further enhancement on the excretion phase (Fig 3D). It was confirmed as MESTK by histopathological staining with the epithelium and stroma (Fig 3E) and immunohistochemical staining (Fig 3F: positive for smooth muscle actin, representing the stromal area; Fig 3G: positive for pan-cytokeratin, representing epithelial areas). The lesion (Case 13) was classified into type A according to the equation.

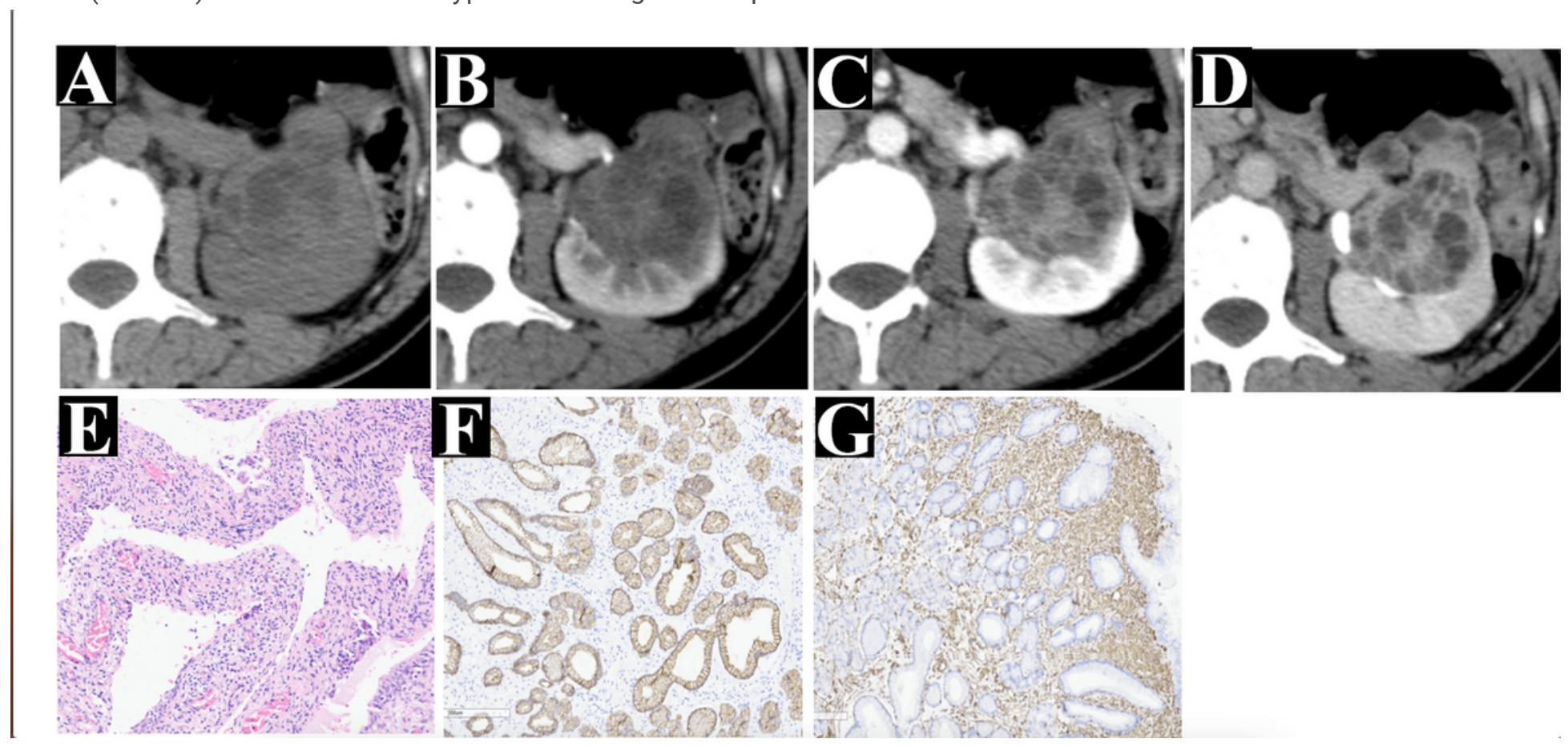

\section{Figure 4}

A 49-year-old woman with flank pain (Case 15), A cystic-solid mass is shown on an axial enhancement MDCT (Fig 4A), which displayed slight enhancement with multi-septate cystic and solid components on the corticomedullary phase (Fig 4B), prolonged enhancement on the nephrographic phase (Fig 4C) and the excretory phase (Fig 4D), and was confirmed as MESTK by histopathological (Fig 4E) and immunohistochemical (Fig 4F: the positive for pan-cytokeratin in the epithelium; Fig 4G: positive for vimentin in the stromal area). The patient (Case 15) was classified into type B (IV category). Compared with Fig 3 (Case 13), it has a variable proportion of cystic and solid components.
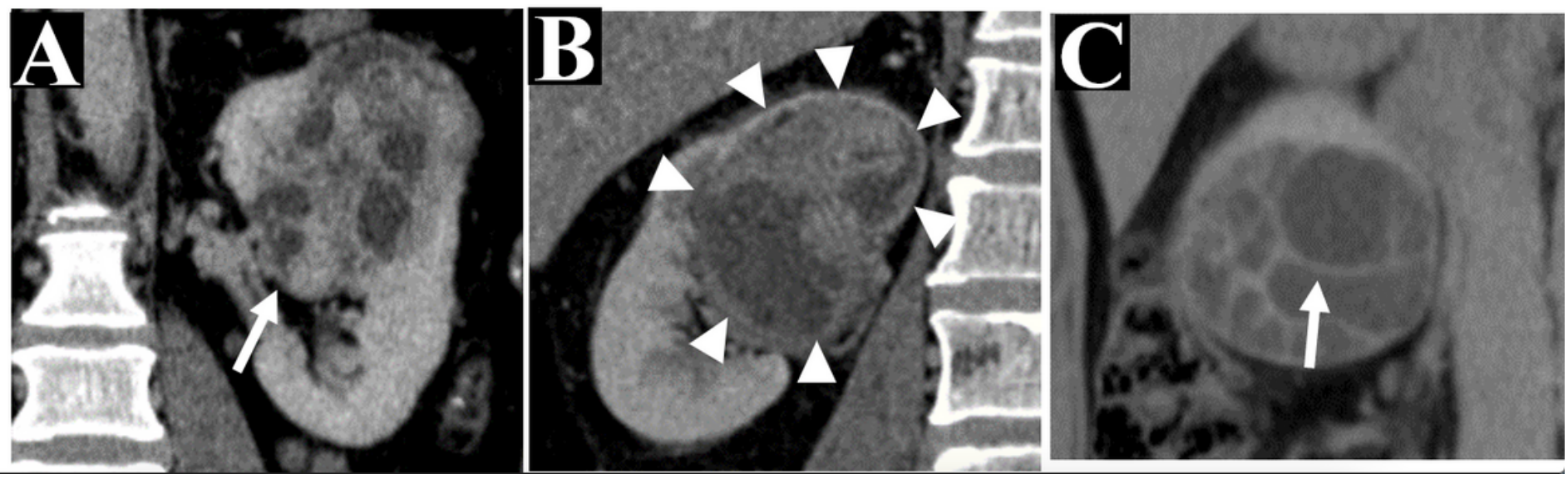

\section{Figure 5}


Some vital imaging features on MDCT. Renal sinus fat invagination (SFI) (white arrow) is shown on the sagittal MDCT (Fig 5A, case 7), which represents the tumor invasion into the sinus fat (white arrow). In addition, the capsule of the tumor (white triangle) is shown on a coronal MDCT (Fig 5B, case 12 ), and the multiple regular septa (white arrow) is shown in the tumor in the coronal MDCT (Fig 5C, case 11).

\section{Supplementary Files}

This is a list of supplementary files associated with this preprint. Click to download.

- Additionalfile1.mp4

- Additionalfile1.docx 